\title{
The Usage of Cloud Computing in Education
}

\author{
Mohammed W. Nofan \\ Department of Computer Science \\ College of Computer Science and Mathematics/ Tikrit \\ University \\ Tikrit, Iraq \\ Moha_wn@yahoo.com
}

\author{
Amar A. Sakran \\ Information Technology Center \\ University of Information \\ Technology \& Communications \\ Baghdad, Iraq \\ amarabedrba@yahoo.com
}

\begin{abstract}
Cloud computing-based technology has become in many modern organizations concerned with education institutions. It will likely have a significant impact on the educational environment in the future. Universities take advantage of available cloud applications offered by service providers and enable their own users/students to perform business and academic tasks.
\end{abstract}

In this paper, reviewing what the cloud computing infrastructure will provide, a literature review providing the context from the infrastructure, application and services aspect of cloud computing, it was also look for the answers of its benefits to higher education institutions and different educational uses. Also introduce cloud computing to educators and help them to gain a better understanding of the conception of cloud technology and its impact on teaching and learning in institutions.

Keywords-Cloud computing; educational institution; SaaS; PaaS; IaaS

\section{INTRODUCTION}

The future we facing a future where the majority educational services will be hosted in the cloud and the institutions will no longer host their own data centers with expensive hardware, power bills, staff salaries and computing resources which are rarely fully utilized?

The highly Evolution of cloud computing are likely to mean an increasing farther away from existing institutions system services. These services are increasingly provided using Internet technologies to staff and students and accessed from web browsers. The services are offered cheap or free for education, often with much higher availability than can be provided by the educational institution[1].

The Term of "Cloud Computing" become an important term in the world of Information Technology (IT). Cloud Computing is a kind of computing which can use virtual resources that can be shared with the other users. Users do not need a lot of information or any background knowledge of the services[1].

Cloud computing is currently one of the new technology. That will likely have a significant impact in teaching and learning environment.

Today, Microsoft and Google are providing free services to students and staff at educational institutions which include email, contact list, calendars, document storage, creation and sharing document and the ability to create website[2].

\section{DEFINITIONS AND CHARACTERISTICS OF CLOUD COMPUTING}

\section{A. Cloud Computing Definitions}

Cloud computing is not always clearly defined is a subscription-based service where you can obtain networked storage space and computer resources[3].

The easy way to understanding of cloud computing is to consider the experience with email. The email client (Yahoo, Gmail, Hotmail, etc...), When you want to access your email you open your web browser, go to the email client, and log in. The most important part of the equation is having internet access.

The emails are not stored on the physical computer, it can be accessed through the internet connection and can be access it anywhere. The email is different from software installed on the computer, such as a word processing or PDF program. Creating a document using word processing software, that document stored on the used device to make it physically move. An email client is similar to how cloud computing works. Except instead of accessing just the email, it can be choose what information that have access to within the cloud.

\section{B. Characteristics of Cloud Computing}

There are various definitions of cloud computing but most commentators agree on several key characteristics:

\section{- Remote data centers}

Cloud services are delivered via the Internet from highspecification data centers in locations remote from the end user and their institution. The server farms have features such as the latest cooling systems and service optimization techniques which individual educational institutions are unlikely to be able to afford. The data centers are often located near cheap sources of electricity. Their locations are not necessarily knowsn to the user, though in some cases users 
require services to be located in specified countries due to data protection legislation[4].

- Pooling of resources

Resources such as data storage, processing, memory and bandwidth are shared between multiple customers and can be allocated dynamically depending on demand. Individual hardware components can be replaced without impacting on performance or availability. Resources may even be spread across multiple data centers to provide better security and resilience[5].

\section{- Infinite scalability}

A key feature of cloud computing is its rapid elasticity, allowing for sudden peaks in demand and giving the customer the impression that the services are infinitely scalable. If the institution wishes to increase use suddenly there is no need to purchase additional hardware which could take weeks and may later be underutilized[6].

\section{- $\quad$ Pay per use}

Customers simply pay for the services they use while providers bear the costs of hardware and software provision. Pricing may vary depending on the time of day due to peaks in demand or varying electricity costs and institutions may therefore carry out certain activities when costs are cheaper. However distributed cloud networks may enable providers to smooth out demand globally and offer uniform pricing strategies not dependent on timing[6].

\section{- $\quad$ Self service}

Customers can decide what resources they wish to use, and increase or decrease these without discussion with the provider. Reporting facilities are provided so that customers can monitor resource usage[5].

\section{TYPES OF CLOUD COMPUTING}

Cloud computing services are generally regarded as falling into three separate categories or levels. The lowest level is sometimes known as infrastructure as a service (IaaS). Here customers can rent basic computing resources such as processors and storage, and use them to run their own operating systems and applications. Amazon's Elastic Compute Cloud is a one example; organizations can use this infrastructure to run Linux servers on virtual machines and scale up usage as required [7].

Platform as a service (PaaS) is the next level up. This enables customers to install their own applications using a platform specified by the service provider. An example here is the Google Apps Engine where developers can write and install applications using the Python language.

The highest level of cloud computing service is known as software as a service (SaaS)[7].

Currently this is the most interest topic in education. The users required only a web browser and internet connection and can reaching the data stored in the cloud and the applications too.

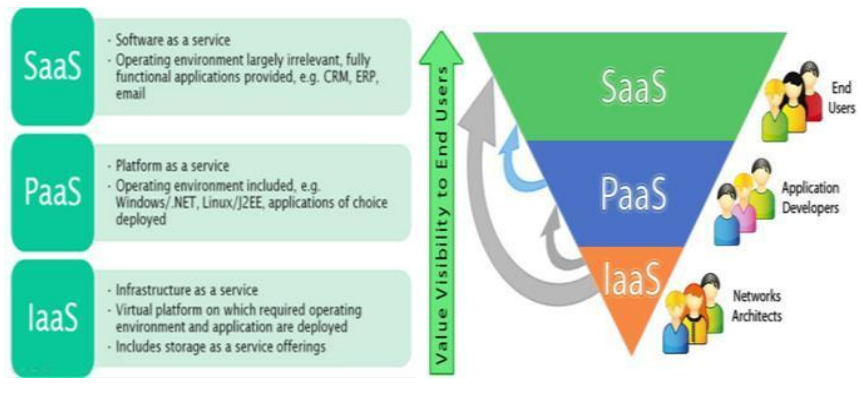

Fig.1: Cloud Computing Types

\section{Cloud Computing IN EducAtion}

A new topic in the rapidly evolving technology world, made the cloud computing has a significant impact onto the modern education sector.

Most people do not have the knowledge and still find the concept of cloud computing very confusing, educational institutions all around the world have embraced the new technology in most processes such as admission, collaborative, teaching and learning [8].

\section{A. How educational institutions use the cloud}

The cloud has already demonstrated its impact on different industries and is now set to take over the education sector. Over the last few years, educational institutions all over the world have started using and turning to cloud technologies.

In 2012, surveys revealed that only $6 \%$ of the institutions were using the cloud in the past two years. Today, we see a great number of schools and colleges using servers or applications provided by Microsoft, Google or Amazon [9].

The three trends that seem to have emerged with the development of web technologies are mobile learning, massive open online courses (MOOCs) and online language learning.

\section{B. The challenges of using cloud computing in education}

Often a school will have competent IT technicians and a vision of IT requirements, but the gap is the strategic vision and understanding of available technologies versus budgets available to deliver on that vision.

The head teacher sits much like a chief executive at the top of the tree. But unlike a public limited company (PLC) chief, the head teacher has very little or no real interest in systems. This is where the gap lies.

\section{- IT vision must reach to the top}

Old teachers have little IT Knowledge and vision which could help guide their IT deliverables. IT does not command the same importance as other more traditional areas of school life; it is largely ignored[8]. 
There must be a fundamental shift in thinking, so that there will be an opportunity for technology to be useful in Education

Technology vendors and service providers must work to reposition IT within the mind-set of the professionals working in the education sector[9].

IT departments or county IT advisers must promote the head teachers by demonstrating the tangible benefits of IT into the Education, that the ways it improves the educational experience for students, teachers and parents.

\section{- $\quad$ Build IT and services curriculums}

The challenge that faced the educational institution that traditional outcomes of both a curriculum and administration network remain within the institution system. One of the challenges are how to delivering data outside of the secure network and allow the student and researchers to access the information and data from anywhere. this is the meaning of private cloud, but these clouds provide just the required data without the required application[9].

Microsoft and other providers are starting to position their cloud offerings to the educational institute, but there are difficulties. For example, Office 365 does not currently give the teaching staff easy access to completed work uploaded by pupils.

\section{- $\quad$ Partner with expert solution providers}

The educational institute needs to look beyond its own IT staff for assistance. Selecting a service provider has knowledge and experience that can provide both initial and ongoing assistance[9].

This may lead to a new age of education supplier or IT offerings which acutely fit the specific needs of the educational institution and communicate with learning systems in a language that is not alien to them.

In these days, service providers that can help the IT professional to succeed is to use modeling and simulation and cloud computing in education are few and far away.

The support of service providers will become more important for the educational institutions consideration the wider impacts such as data protection.

\section{- Develop the existing infrastructure}

For sizable institution that have large infrastructures onsite, transition to cloud computing services may be difficult or far away.

So the challenge will be to update and enhance the computing, networking and storage resources that the institution already has.

for the storage as an example, if some of the education institution started to use the video camera for recording the lecture and stored the video conferences, the IT administrator that the video files was take a lot of space and that file size came from replicated the files during the students shared and saved their work[10].

Deduplication do not depend the block level, or number of files, it has huge role within the educational institution because it can maximize available storage and to prevent losing the capital investment in more storage devices and space.

\section{- Convince in-house IT staff to work together}

Prevailing belief that there is not enough collaboration between various IT staff members for educational institute. There is a few readiness for IT expert to working from the various institution in the educational field with the other to find ways to improve.

with the developed resources and skills of the IT staff, this new technology was successfully introduced which was remarkable, If the institutes' IT collaboration today, swapped best practices and experiences, and sought collaboration through combined cloud services, this would lead to more creative and efficient use of IT funds and expertise[10].

\section{The ADVANTAges OF USING ClOUd COMPUTING IN EDUCATION}

\section{A. Potential Cost-savings}

Moving to the cloud usually means moving away from a CAPEX model (physical assets that depreciate) to an OPEX model (pay per use). Cloud services could be a cheaper option, yet still have to invest in IT technology to improve learning standards[10].

If a educational institution that currently save its software and data in a local server, moving to the cloud will allow them to spread out IT costs through flexible subscriptions. Such software as a service it can shared that software with other institute that is a cheaper alternative to the large costs associated with upfront license.

Google and Microsoft's cloud productivity applications allow institute to pay for their cloud programs on demand. For example, Google Apps for Education takes Google's existing cloud-based productivity apps (such as Calendar) and focuses them around collaborative study.

\section{B. Pedagogical Benefits: Increase Engagement and Productivity}

Cloud services complement what research has discovered about those benefits: how their mobility and flexibility leads to

greater collaboration and engagement. With cloud computing, the programs used to create and share become even more mobile and less tethered to a particular device, exponentially increasing the pedagogical benefits.

In the SafeGov.org, which is a forum for cloud, computing industry experts and decision-makers to discuss, promote, and advance trusted and responsible solutions for the public and private sectors. SafeGov.org report, $51 \%$ of 
staff surveyed envisioned benefits such as better exam results[6].

The portability of mobile helps remove barriers to learning by enabling ease and speed of use.

This led to increased engagement and collaboration since students were able to continue working and studying at home or during movement.

The gap between institute and home was shortened. Cloud computing would increasing shorten this gap.

\section{Privacy and Security Concerns}

the very features that make cloud computing perfect choice for education (the ability to collaborate, ease of accessing homework files) hosting companies being able to control communication between the institute and the student. Continuous access to student data raises privacy concerns. SafeGov.org found that $74 \%$ of teachers saw threats to privacy as the top risk, followed by security breaches $(70 \%)[11]$.

Not only allow companies monitor student data, but the possibility of data mining (extracting user information).

According to SafeGov.org, $81 \%$ of teachers would reject cloud business models that allowed providers to mine data from emails and documents.

Instead of decide against cloud computing, institute could ensure using privacy protections. Solutions could include cryptography or using multiple cloud providers.

\section{STARTING CLOUD COMPUTING IN EDUCATION}

\section{Many}

educational institutions have begun their movement to cloud computing by outsourcing their student email provision. Email is a basic, somehow standardized service, can be provided easily by third parties, it's not core to the educational mission. Both Google and Microsoft offer email services for free to the educational sector in many countries [11].

These two companies provide email as a part of larger application which are usually made available to students Side-by-side with email.

Google Applications for Education and Microsoft Live@edu contain other communication tools such as instant messaging along with contact management and calendar software. There are also document creation applications allowing the production of word-processed documents,

spreadsheets and presentations as well as the ability to create websites[11].

These can all be edited collaboratively with other users. Significant storage space for documents of all types are offered to users who can continue to use these once they leave the institution.

Her became the question: Why are the services provided for free to educational institutions? There are a number of advantages to companies who are currently competing for market share.

Software has always been provided cheap and discounted to the educational sector and service company (providers) seek to build relationships with the institutions which provide their future employees.

In addition they are building brand awareness and loyalty which may lead to the selling of other or premium services to institutions and users in the future.

A student seeing the benefit of these tools may persuade a future employer to invest in this commercial field which provide a more incomes source to the cloud providers.

Educational institutions are also beginning to use lower level cloud services for specific purposes such as data storage. This may be interesting where data security is of lower concern such as where video and audio is provided as open educational resources.

Another use of cloud computing which is beginning to emerge in education is for the hosting of institutional learning management systems (LMSs) in the cloud. Outsourcing the provider of LMSs such as Blackboard that makes the institutions who cannot justify the costs of purchasing, maintaining and supporting hardware and software themselves.

\section{BENEFITS OF CLOUD COMPUTING FOR INSTITUTIONS AND STUDENTS}

Despite all the benefits that has cloud computing, many educational institutions fight to overcome potential difficulties. These are mostly related to the fact that not all the necessary application run in the cloud, security risks associated with the cloud, standards commitment, and the like[12].

In Tikrit University over recent years provided IT knowledge and services to support the onsite IT team such as using E-learning technology, online exam, Ibn-Sena center for virtual learning, online lectures and virtual science library, E-Management and online register for student. The relationship has seen the successful introduction of virtualized servers and desktops bringing resilience and clear operational benefits for staff and student alike. introducing new curriculum software applications into the classroom is a simple and speedy process. When the teacher sees IT as an integral element of teaching

then the way towards using cloud computing in education can be led to high knowledgeably of IT and cloud concept[7].

It is clear that the mobility and flexibility offered by cloud to enhance learning. In addition to potential costsavings, making it an attractive option for educational institution. Many teachers and educators has poor knowledge about "cloud" and what it really means. Below a quick review to the benefit of cloud computing and how it enhances the education procedure. it will be clear that there 
are some major potential benefits to institutions deploying cloud services[11].

\section{- Economies}

The economic is the primary advantage for many institutions. This is particularly clear where services such as email are offered for free by external providers. for such services can be deployed or removed, potentially the increasingly valuable at a premium in settings such as city center university campuses. Personnel costs can be cut or staff redeployed. The fact that institutions pay per use instead of often underutilized hardware is appealing.

\section{- Elasticity}

A second major benefit is the elastic facet of cloud computing discussed earlier. This allows institutions to begin with small-scale services and build them up gradually without significant up-front investment. It also allows for rapid escalations in demand at times such as at the start of the academic year or during exam periods. There is therefore no need to plan usage levels in advance.

\section{- Enhanced availability}

A further benefit is that availability may be higher with less downtime due to the superior resources and skills available to cloud providers. Whereas a university computing service department may aim to achieve $99.5 \%$ availability for its educational services such as the LMS, Google offers $99.9 \%$ availability for its educational application suite and appears to outperform this target. Students increasingly dependent on online services for learning and assessment should be given the best possible availability.

\section{- Lower environmental impact}

In some countries there are now "green" targets for reductions in power usage by organizations. Cloud computing enables educational institutions to reduce their own electricity consumption and, in theory, cloud providers should be able to optimize power usage over a group of customers. However it is not easy to obtain figures for power usage from cloud providers and it is likely that their power consumption worldwide is growing significantly.

\section{- Concentration on core business}

Another claimed advantage of cloud computing is that it allows institutions to concentrate on their core business of

education and research. Schools and universities do not normally have their own sewage plants and power stations;

similarly it can argued that computing services are becoming commoditized and are handled better by organizations with specific expertise and economies of scale.

\section{- $\quad$ End user satisfaction}

For end users, apart from better availability, there are other clear benefits of cloud services, particularly evident with the range of new applications being provided. These contain the latest tools and features from companies such as Microsoft and Google. Students can use office applications for free without having to purchase, install and keep these applications up to date on their computers. Possibilities for collaboration are greatly enhanced. They do not have to worry about backing up or losing data as it should be safely stored in the cloud - with large storage capacity provided for free. Their data is accessible to them from any location or from a range of devices such as their mobile phone.

\section{RISKS OF CLOUD COMPUTING}

Cloud computing is a new paradigm which is threatening to some individuals in institutions. It challenges computing service personnel who may fear the consequences of their roles being outsourced. Senior managers may feel uncomfortable about transferring the hosting of business data and services outside the institution. Thus some risks may be more to do with perception than reality[11].

Data security: A major concern is around the security of data. Institutions may consider that their data is more secure if it is hosted within the institution. Transferring data to a third party for hosting in a remote data center, not under the control of the institution and the location of which may not be known presents a risk.

Some cloud providers now provide guarantees in their contracts that personal data will only be stored in particular countries. The primary risk here is that there will be a breach of confidentiality

\section{FUTURE OF CLOUD COMPUTING}

The lateness development of educational institutions and their risk averse nature means that they are to be slow to migrate services to the cloud.

As bandwidth increases globally and increasing numbers of students have adequate access to the Internet, they will become more comfortable with using rapidly evolving webbased applications and storing their data online rather than on their own storage devices which are more likely to be lost or damaged. Demand for cloud applications may therefore be driven by users rather than by institutions.

The increased use of lower level cloud services in education such as for data storage seems certain, particularly for services where security is not the main issue such as for repositories of learning content. While some universities will wish to maintain their expertise in hosting computing resources for research and teaching purposes, this may

increase costs which most educational institutions prefer to do without.

\section{conclussion}


Cloud computing as an exciting development is a significant alternative for the educational Perspective. Using the cloud is reduces the cost of organizational or institution expenses and offers more powerful functional capabilities. Removal of software license, hardware and maintenance costs provides greater flexibility to the educational institution management. using cloud eliminates disaster recovery risks and its high costs. Cloud computing is definitely one of the major innovations that entered worldwide classrooms in recent years.

There are some disadvantages too. The cloud computing services needed to deliver the majority of IT services needed by customers do not yet exist. All of the cloud providers do not have the same capability for their technological levels. With the ability of reducing the IT costs and at the same time create a modern collaborative environment, educational institutions can see some important benefits from moving to the cloud.

Using the modern way for learning processes and introducing the latest technologies in education encourage students to develop skills and knowledge necessary for achieving the academic and professional goals. The cloud can substantially increase learning opportunities for students all

over the world, and eventually contribute to equipping future generations with skills and competencies necessary for international career advancements.

\section{References}

[1] Armbrust M et al (2009) Above the clouds: a Berkeley view of cloud computing. UC Berkeley Technical Report.

[2] Educause (2010). Cloud Computing. Retrieved Oct 10, 2010, from http://www.educause.edu/Resources/CloudComputing/

[3] Alexa Huth and James Cebula, "The Basics of Cloud Computing", 2011 Carnegie Mellon University. Produced for US-CERT, a government organization.

[4] http://www.cs.berkeley.edu/ rxin/dbpapers/WarehouseScale Computing.pdf

[5] http://www.isaca.org/groups/professional-english/cloudcomputing/groupdocuments/essential\%20characteristics $\% 20$ of $\% 20 \mathrm{clo}$ ud\%20computing.pdf

[6] M. Armbrust et al. Above the clouds: A berkeley view of cloud computing. Technical Report UCB/EECS-2009-28, 2009.

[7] Pankaj Sareen," Cloud Computing: Types, Architecture, Applications Concerns, Virtualization and Role of IT Governance in Cloud", International Journal of Advanced Research in Computer Science and Software Engineering, Volume 3, Issue 3, March 2013.

[8] The ABC'S of Engineering of education: ABET, BLOOM'S TAXONOMY, COOPERATIVE LEARNING, AND SO ON.

[9] http://www.cloudwards.net/beyond-business-collaborationhow- educational-institutions-use-the-cloud/

[10] Utpal Jyoti Bora, Majidul Ahmed," E-Learning using Cloud Computing", International Journal of Science and Modern Engineering (IJISME) ISSN: 2319-6386, Volume-1, Issue-2, January 2013.

[11] http://iite.unesco.org/pics/publications/en/files/3214674.pdf

[12] IBM Global Technology Services, " Applying the cloud in education". 